\title{
Diversification for enhanced food systems resilience
}

\author{
At the field, farm, household and market levels, multiple options exist for diversification of activities, building \\ resilience of food systems to stresses and shocks.
}

Thomas Hertel, Ismahane Elouafi, Morakot Tanticharoen and Frank Ewert

G lobal change and an increasingly interconnecting society are inducing unprecedented hazards likely to prove disastrous for many of the world's most vulnerable populations. Food systems are at the heart of this challenge and must become more resilient to ensure access to food while also providing livelihoods for a large share of the world's poorest households ${ }^{1}$. A resilient food system must be financially equitable (economic resilience), supportive of the entire community (social resilience) and it must minimize harmful impacts on the natural environment (ecological resilience). The United Nations Food Systems Summit 2021 designated resilience as one of its five Action Tracks. While reviewing this subject for the Summit ${ }^{1}$, one central theme emerged - the importance of diversification.

Diversification of the food system can occur across the entire supply chain and at different levels of organization (Fig. 1). To illustrate its influence on resilience, we focus our Comment on the diversification of production and markets, as well as household income, highlighting research gaps and challenges for its adoption.

\section{Diversification of production}

Diversification of food production, particularly of crops and cropping systems, has received increasing attention in recent years ${ }^{2}$ as a means of building resilience to climate change and increasing extreme weather events, and also to improve the ecological performance of crops, reducing their harmful impacts on the climate and the environment ${ }^{3}$. Evidence also shows that biodiverse ecosystems are capable of delivering additional ecosystem services without compromising crop yields ${ }^{3}$ or even with benefits for crop production ${ }^{4}$.

Diversification of production should encompass different levels of the organization (Fig. 1). Agroecology, an approach receiving increasing attention in research and agricultural practice, attempts to explicitly leverage the benefits of agroecological relationships
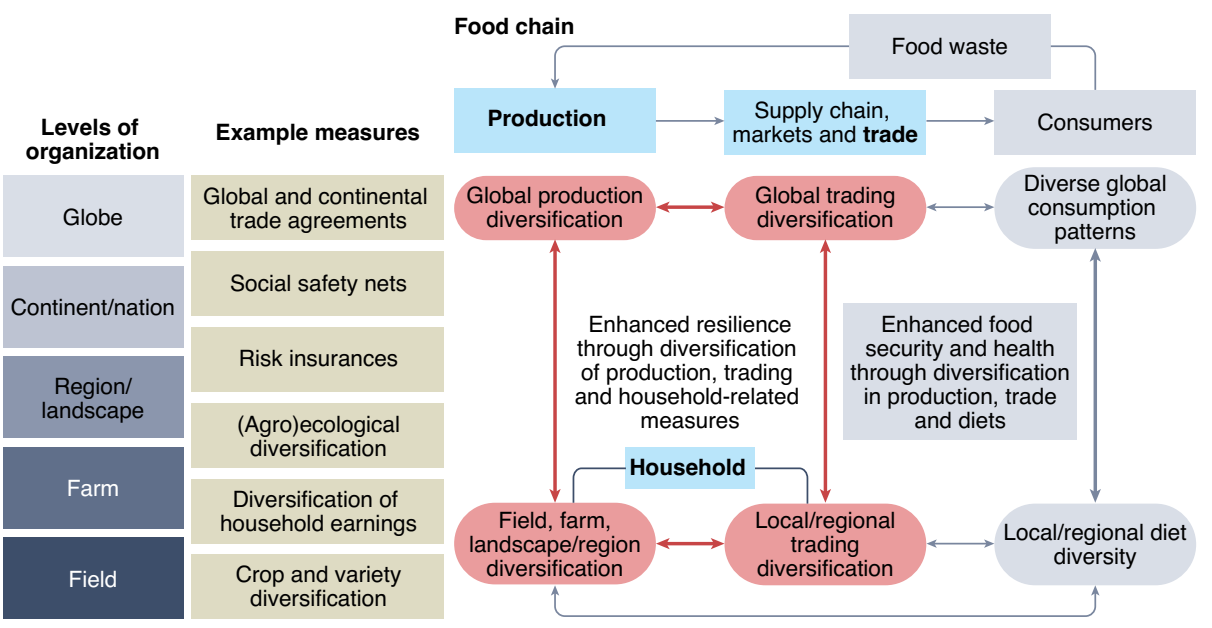

Fig. 1 | Food system diversification to enhance food systems resilience. Across levels of organization, from field to global, and along the supply chain, from production to consumption, diversification measures may enhance food systems resilience. Note that diversification of food processing and diets are not addressed in this Comment, but are closely related to diversification of production, household livelihoods and trade. In general, relationships (trade-offs and additional benefits) among diversification measures across scales and along the food supply chain are not yet well understood and deserve more attention.

and diversification at the field, farm, landscape and regional scales and up to the broader food system ${ }^{5}$. However, while diversification of crops and cropping systems has frequently been investigated ${ }^{2}$, diversification of agricultural landscapes and regions also deserves consideration as it has many beneficial effects on biodiversity and ecosystem services ${ }^{6}$.

Any attempt to integrate approaches in order to diversify production across organizational levels will need to go beyond the land-based production subsector to encompass other subsectors such as aquaculture, and vertical and urban farming. The importance of aquaculture as an integrated part of the global food system has been highlighted and in some regions, for example in Asia, food contributions from inland aquaculture are critically important ${ }^{7}$. However, despite progress in recent years, issues remain regarding the sustainability of production and the development of markets jointly with other production sectors to improve food systems resilience.

The concrete solutions for diversification of production will depend on the local and regional natural environment (for example, soils, climate and geography) but also on the socio-economic and cultural conditions determining present farming systems. Understanding the ecological-economic trade-offs of diversified farming systems is crucial for successful diversification strategies. Positive outcomes of crop diversity for agricultural employment worldwide have been reported, but the economic costs of diversifying farming systems often outweigh the ecological benefits ${ }^{8}$. There is a need for adequate policies to support the development of diverse and sustainable (ecological, economic and social) production and farming systems, and households ${ }^{9}$. 


\section{Diversification at the household level}

A key goal of the food system is to enhance the well-being of individuals and the households to which they belong. This requires a household-centric view of diversification and resilience. Given the prominent role of income in ensuring household well-being, diversification of income sources is critical. Three important sources of income diversification are risk management, safety nets and labour market diversification.

Diversification across states of nature. With extreme weather events expected to become more frequent in the future, new forms of risk management will be needed. Traditional methods of community-based risk sharing are no longer viable when entire communities face common risks from drought, flooding and heat stress. Weather index insurance has been developed specifically for such circumstances ${ }^{10}$. Households enrol at the beginning of the season and payouts for all farmers in the disaster-affected region are made when an index, for example rainfall in the region, drops below a pre-determined trigger level. This allows households to diversify their incomes across different 'states of nature', paying out money when the weather is normal and receiving money when drought or flooding disasters strike. This form of diversification has great potential to stabilize rural agricultural household incomes.

Since its inception, weather index insurance has faced challenges in reaching the poorest households - as they typically confront severe credit constraints. However, recent technological innovations such as remote sensing and e-banking are enabling index insurance to thrive across the developing world. India and China, where $80 \%$ of all farms have some form of insurance, have led the way ${ }^{11}$. In Africa, where $70 \%$ of the programmes are private sector led - albeit often in partnership with the public sector - this market penetration is still very small. One of the most successful programmes is the Agriculture and Climate Risk Enterprise (ACRE) programme that has reached more than 1.7 million farmers in East Africa. ACRE works with local institutions such as cooperatives and agricultural finance providers to reach individual farmers ${ }^{11}$. ACRE weather index insurance has allowed three-quarters of participants to access credit that would otherwise have not been available to them due to the risk of catastrophic losses. While promising, reaching its full potential will also require education about the benefits of insurance as well as improved historical weather information that is still scarce in much of the region ${ }^{11}$.
Social safety nets. While weather index insurance provides an important source of income diversification for agricultural producers, it does not directly benefit non-farm households and fails to shield net buyers of food from food price spikes in the wake of extreme weather events. For these households, other social safety nets can play an important role. While widespread throughout much of the world, social protection programmes have only recently emerged on the scene in Africa where they are rapidly expanding ${ }^{12}$. This trend has been further accelerated in the context of the coronavirus disease 2019 (COVID-19) pandemic.

While social assistance and social insurance can be viewed as sources of income diversification in their own right, recent research suggests that such programmes can also have important impacts on households' livelihood strategies. By providing an assured source of income, social protection can reduce the risk associated with investments in new activities, including increased participation in commercial agricultural markets and increased farm productivity, as well as increased engagement in non-farm activities ${ }^{12}$. In a recent study of the Harmonized Social Cash Transfer programme targeting ultra-poor, labour-constrained households in remote, rural Zimbabwe, Pace et al. find significant impacts on income diversification over the medium run (four years) (manuscript in preparation). Specifically, they identify a shift from survival-led diversification, driven by seasonality, climatic uncertainty, land constraints and limited market access, to opportunity-led diversification, including higher-paying non-farm activities, with attendant increases in food and non-food consumption.

\section{Rural-urban migration and income} diversification. While rural off-farm work can provide important income diversification opportunities, many rural households also choose to send one or more family members to work in urban areas. Rural-urban migration has been a long-standing means of diversifying and raising household income, with remittances from migrants to their communities of origin helping to ensure food security, reduce poverty, support children's education, ease credit constraints in farming, pay for farm inputs and repay debts ${ }^{13}$. Furthermore, when an urban disaster arises, such as the East Asian financial crisis of 1997, the rural household connection can provide an important safety net.

The importance of migrants' remittances to rural household well-being has been underscored during the COVID-19 pandemic. Border closures and lockdown restrictions have resulted in a significant loss of jobs and economic activities throughout much of the developing world. Consequently, these remittances, a vital source of income for the rural villagers, have been largely lost ${ }^{14}$. Thus, not only has the pandemic worsened poverty and inequality, it is also likely to leave long-lasting scars on labour markets, reversing progress on poverty and income inequality in many economies and reducing resilience.

\section{Diversification through trade}

Weather index insurance, safety nets and household income diversification are necessary to ensure households' food security, but they are not sufficient in the face of widespread weather disasters such as droughts and flooding that may jeopardize local and regional food availability. Here, robust markets and trade play a critical role in ensuring food security. There is perhaps no better illustration than that provided by pre-colonial India, where weather-induced famines were common, resulting in tens of millions of deaths. However, with the introduction of railroads in colonial India, large-scale interstate trade became possible and there was a dramatic reduction in the number of deaths associated with extreme weather events; improved market integration greatly enhanced food security by allowing for timely imports from food-surplus regions $s^{15}$.

Trade among nations can play the same role - mediating between food-surplus and food-deficit regions in the face of scarcity. However, this is only possible if government and private actors operate under a rules-based system with adequate information provided to everyone engaged in agricultural markets. The potential for markets to be destabilized by panic and misinformation was on dramatic display during the 2006-2008 food crisis when cascading export bans and panic greatly exacerbated the price rises for rice and wheat ${ }^{16}$. These price spikes were particularly severe for consumers in the poorest countries. In the wake of that experience, the G20 ministers of agriculture initiated a multinational, multiagency effort to provide improved market information. Known as the Agricultural Market Information System (AMIS), it documents in detail government interventions - their scope, duration and modification, on a real-time basis - along with up-to-date information on commodity stocks and production. As a consequence, overreactions on the part of governments and markets to the disruptions posed by the COVID-19 pandemic were avoided ${ }^{17}$. 
However, merely documenting these interventions is insufficient. It is important to reach a new multilateral agreement in agriculture that will prevent countries from intervening in markets during these crisis periods.

Of course, it is not enough to integrate national markets into the global economy. Many of the world's smallholder farmers and rural households are poorly integrated into local and regional markets, thus limiting their ability to benefit from intra- and international trade. In Ethiopia, a pilot effort dubbed P4P: Purchase for Progress, run by the World Food Programme, works through farmer organizations in order to better integrate farm households into regional markets. This involves reducing transaction costs and improving information flows. A recent study of the $\mathrm{P} 4 \mathrm{P}$ pilot project in Ethiopia finds that these interventions have boosted spending by participating households by $25 \%$ - as well as sharply increased investment in children's education ${ }^{18}$. This effort has benefited not only short-term resilience, but also long-term development and poverty-reduction objectives.

\section{Conclusions}

While there are many different avenues to obtain greater food systems resilience, we believe that the most fundamental of these is diversification, which can occur at many different levels and across components of the food system. This Comment has focused on diversification of agricultural production and trade and on household-related responses. However, equally important for food systems resilience will be diversification along the entire value chain as well as in consumption. Diversity in diets is a critical element for ensuring healthy consumer outcomes, while also carrying important implications for patterns of production and trade.

In closing, it should also be noted that many of the elements discussed in this Comment interact in important ways. For example, while increased production risk will encourage farmers to diversify, greater market integration encourages specialization in production in order to increase expected household income ${ }^{19}$. Clearly, the relationships among diversification of production and other parts of the food system, particularly diversification of diets and markets including market access, are not straightforward and need more attention ${ }^{19}$. Food system modelling frameworks to assess resilience are at an early stage of development ${ }^{20}$ but can be helpful in integrating the complex interactions between food, ecology, economy and society, thereby providing advice on critical trade-offs when diversifying food systems to improve their resilience.

Thomas Hertel(D1凶, Ismahane Elouafi², Morakot Tanticharoen ${ }^{3}$ and Frank Ewert ${ }^{4,5}$ ${ }^{1}$ Department of Agricultural Economics, Purdue University, West Lafayette, IN, USA. ${ }^{2} U N-F A O$, Rome, Italy. ${ }^{3}$ School of Bioresources and Technology at the King Mongkut's University of Technology Thonburi, Bangkok, Thailand. ${ }^{4}$ Leibniz Centre for Agricultural Landscape Research (ZALF), Müncheberg, Germany. ${ }^{5}$ University of Bonn, Bonn, Germany.

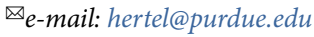

Published online: 9 November 2021

https://doi.org/10.1038/s43016-021-00403-9
References

1. Hertel, T. W., Elouafi, I., Ewert, F. \& Tanticharoen, M. Building Resilience to Vulnerabilities, Shocks and Stresses. A Paper on Action Track 5 https://doi.org/10.48565/scfss2021-cz84 (Center for Development Research (ZEF) in cooperation with the Scientific Group for the UN Food System Summit 2021, 2021).

2. Hufnagel, J., Reckling, M. \& Ewert, F. Agron. Sustain. Dev. 40, 14 (2020).

3. Tamburini, G. et al. Sci. Adv. 6, eaba1715 (2020).

4. Dainese, M. et al. Sci. Adv. 5, eaax0121 (2019).

5. Wezel, A. et al. Agron. Sustain. Dev. 34, 1-20 (2014).

6. Tscharntke, T., Grass, I., Wanger, T. C., Westphal, C. \& Batáry, P. Trends Ecol. Evol. 36, 919-930 (2021).

7. Naylor, R. L. et al. Nature 591, 551-563 (2021)

8. Rosa-Schleich, J., Loos, J., Mußhoff, O. \& Tscharntke, T. Ecol. Econ. 160, 251-263 (2019).

9. A Multi-billion-dollar Opportunity-Repurposing Agricultural Support to Transform Food Systems (FAO, UNDP \& UNEP, 2021)

10. Hazell, P. B. R. et al. The Potential for Scale and Sustainability in Weather Index Insurance for Agriculture and Rural Livelihoods (IFAD-WFP, 2010).

11. Innovations and Emerging Trends in Agricultural Insurance: An Update (GIZ, 2021).

12. Correa, J. S., Daidone, S. \& Sitko, N. in Africa Agriculture Status Report. A Decade of Action: Building Sustainable and Resilient Food Systems in Africa 172-196 (AGRA, 2021).

13. Deshingkar, P. IDS Bull. 37, 88-100 (2006).

14. COVID-19 Crisis Through a Migration Lens https://go.nature. com/3pZKiWD (World Bank, 2020).

15. Burgess, R. \& Donaldson, D. Am. Econ. Rev. 100, 449-453 (2010).

6. Martin, W. \& Anderson, K. Am. J. Agric. Econ. 94, 422-427 (2012).

17. Jansen, M. COVID-19 and the global economy. In 2020 International Agricultural Trade Research Consortium (IATRC) Annual Meeting https://go.nature.com/3jK73g7 (2020).

18. Gelo, D., Muchapondwa, E., Shimeles, A. \& Dikgang, J. Food Policy 97, 101911 (2020).

19. Keenan, M., Karanja, S., Pamuk, H. \& Ruerd, R. Smallholder Farming Households' Make-or-Buy Decisions: Linking Market Access, Production Risks, and Production Diversity to Dietary Diversity (CGIAR Research Program on Climate Change, Agriculture and Food Security, 2021).

20. Müller, B. et al. Glob. Environ. Change 63, 102085 (2020).

\section{Acknowledgements}

T.H. acknowledges support by the National Science Foundation (CBET 1855937 and OISE-2020635) and F.E. acknowledges support by the Deutsche Forschungsgemeinschaft (DFG, German Research Foundation) under Germany's Excellence Strategy - EXC $2070-390732324$

\section{Competing interests}

The authors declare no competing interests. 